\title{
Jaque a la Ley: Referencia a algunas anomalías de la Ley Tributaria(*)
}
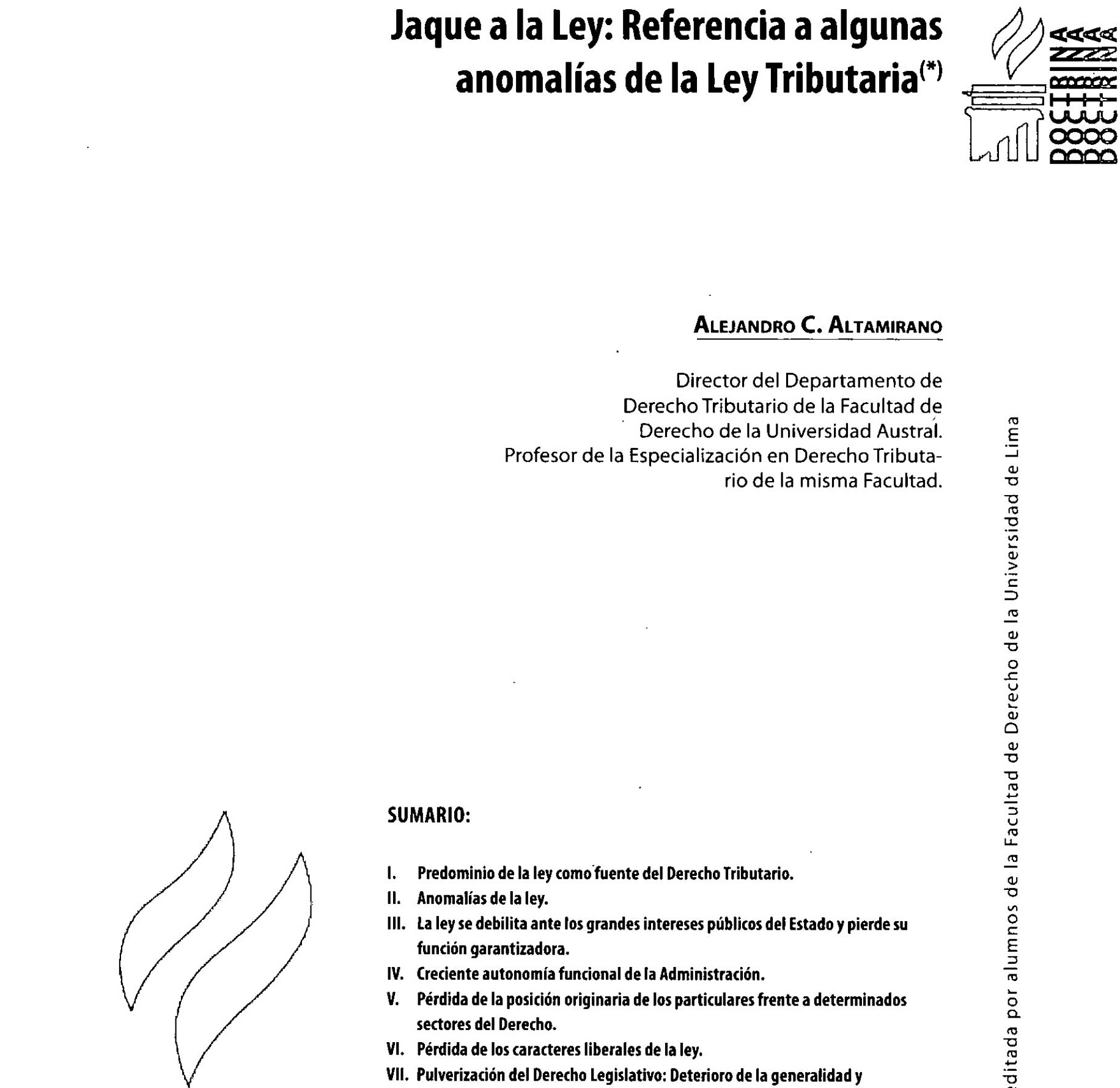

SUMARI0:

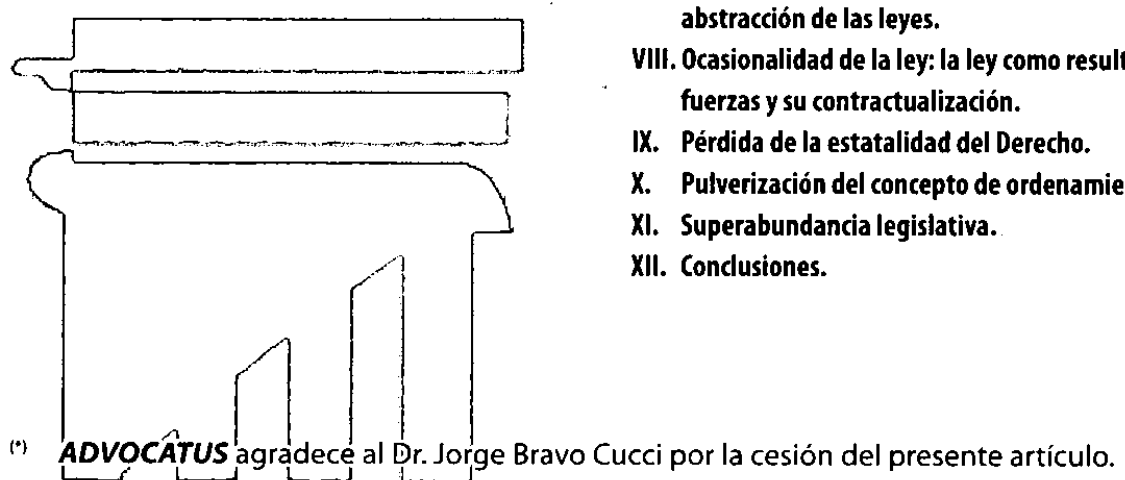

I. Predominio de la ley como fuente del Derecho Tributario.

II. Anomalías de la ley.

III. La ley se debilita ante los grandes intereses públicos del Estado y pierde su función garantizadora.

IV. Creciente autonomía funcional de la Administración.

V. Pérdida de la posición originaria de los particulares frente a determinados sectores del Derecho.

VI. Pérdida de los caracteres liberales de la ley.

VII. Pulverización del Derecho Legislativo: Deterioro de la generalidad y abstracción de las leyes.

VIII. Ocasionalidad de la ley: la ley como resultado de colisiones de

Perdida de la estatalidad del Derecho.

Pulverizacion del concepto de ordenamiento.

XI. Superabundancia legislativa.

XII. Conclusiones. 


\section{PREDOMINIO DE LA LEY COMO FUENTE DEL DERECHO TRIBUTARIO}

Debido a que únicamente la ley puede crear tributos, es autoevidente el rol preponderante, esencial e ineludible que esta tiene como fuente del Derecho Tributario.

Existe una visión idealizada de la ley. Denominémoslo una visión histórica del concepto de la ley. Según esta perspectiva bien difundida, se le atribuye a la ley una fortaleza en su construcción y una efectividad en su aplicación que muchas veces no se ajusta a la realidad. Desde este prisma, se considera a la ley como la expresión de la voluntad general del pueblo que es recogida en normas generales, es decir, formulaciones abstractas aplicables a todos los habitantes por igual sin que se realicen discriminaciones de grupos ni sectores. La ley se proyecta sobre todos de manera generalizada por lo que disciplina a todos los destinatarios por igual. La voluntad general, entonces, contiene el notable resultado de una expresión de la voluntad popular que deviene prácticamente infalible porque el poder legislativo-representante de los habitantes- le brinda los anticuerpos necesarios para inmunizarla de cualquier posible error. La ley es la ley.

Esta incapacidad de error e infalibilidad de la ley en clave rousseauniana, lleva a García de Enterría a recordarnos que Diderot dijo que "las voluntades particulares son sospechosas; pueden ser buenas o malas; pero la voluntad general es siempre buena; no ha engañado nunca, no engañará jamás". Los derechos en la sociedad sepultan a la vieja concepción de que "lo que al príncipe place tiene fuerza de Ley, que hacía equivaler a esta con el producto de una simple voluntad humana superior (para explicar tal superioridad estaban las explicaciones teológicas del poder). Viene a resultar inesperadamente, en virtud del mágico y prodigioso hallazgo de Rous- seau, que la Ley no tiene otro objeto ni produce otro efecto, justamente, que identificar, proteger y hacer efectiva la libertad, articulando la libertad de todos y asegurando su simple coexistencia". Las tesis centrales del paradigma dogmático legalista -dice Vigo- se resumen en que a) el Derecho es creado por el Poder legislativo y se encarna en los códigos; b) el Derecho se da a conocer a través de la publicación oficial; c) el saber jurídico es científico y su objeto radica en clarificar y reconstruir sistemáticamente el derecho positivo; d) la aplicación del derecho (ley) se realiza por un mecanismo de la subsunción y de un elemental silogismo deductivo; e) la Constitución no es algo jurídico sino un programa político, cuyo destinatario es el legislador quien lo juridiza de conformidad con su criterio y f) cualquier otra fuente de Derecho está subordinada a la ley y en el marco del sometimiento a la voluntad del legislador. ${ }^{2}$

Pero a poco que se exploren con detalle estas afirmaciones y se las coloque en el banco de pruebas de la complejidad de las relaciones tributarias, fácilmente se puede comprobar que existe una vasta cantidad de condicionantes, al momento de la sanción de la ley, que poca o ninguna relación tiene con una adecuada y desinteresada tutela del Derecho Tributario. Esto merece aclaraciones sobre las que se avanzará en el siguiente punto al referirnos a las anomalías de la ley.

Caben por tanto una serie de interrogantes. Esta visión histórica de la ley, ¿se ajusta a la actualidad? Ese concepto bucólico de la ley, ¿es predicable en la actualidad? El principio de legalidad es insustituible, innegable e imprescindible para que el Estado constitucional de Derecho funcione, para que se repartan las funciones dentro de los diferentes estratos del Estado y para que los ciudadanos puedan defender sus derechos y libertades. Indudablemente no existe la libertad sin ley que la proteja y no puede existir una sociedad sin ley. En definitiva, una vez más afirmamos que

\footnotetext{
1 GARCIA DE ENTERRÍA, Eduardo, Justicia y seguridad juridica en un mundo de leyes desbocadas, Civitas, Madrid, 1999, p. 28.

2 VIGO, Rodolfo R., De la ley al Derecho, Porrúa, México, 2003, p. 107.
} 
el Derecho es reparto, es dar a cada uno lo que le corresponde y esto solo puede materializarse con un instrumento: la ley.

Somos esclavos de la ley para vivir en libertad, decian los griegos, y esta simple idea puede extrapolarse a la actualidad pues no ha perdido vigencia. La obediencia se exige en tanto exista la ley. No es posible imaginar a la autoridad al margen de la ley. El Fisco goza de las facultades con las que cuenta, por virtud de la ley. No está ni por encima ni debajo de ella sino que ajusta su comportamiento a ella, como también los contribuyentes. Todo el Derecho Público está, por ello, construido sobre este principio de legalidad: el Derecho Penal, el Derecho Tributario, el Derecho Presupuestario, el Derecho Administrativo -en todas sus múltiples derivaciones-, el Derecho de Organización de Tribunales, el Derecho Procesal. La codificación napoleónica (el Derecho decimonónico) como aspiración de un ordenamiento concentrado mantiene su prestigio pero ha perdido la exclusividad y preponderancia que tuvo en el pasado. Seguimos estando inmersos en la atmósfera que los publicistas de Francia denominaron "el reino de la Ley".

Sin embargo con el devenir del desarrollo de las sociedades, de la política, de los intereses, los caracteres intrínsecos de la ley, aquellos datos que nos permiten la más absoluta y plena confianza en este instrumento que disciplina la vida en sociedad, están sufriendo reacomodamientos. La Constitución, como norma máxima de la Nación que encarna los valores sobre los que se construye la sociedad, es un Derecho de mayor envergadura al de la ley. La Constitución, a su vez, hunde sus raíces en el Derecho natural prevalente a las normas que emanan del Congreso. Y este cambio de perspectiva, en gran medida se debe al constitucionalismo americano y su enorme influencia en el constitucionalismo mundial. Es decir, el Derecho decimonónico fuertemente atado al positivismo cede espacio en favor de los principios, y así el Derecho avanza.

Enseña García de Enterría que,

\section{"(...) la idea de la Constitución como una norma} superior, que consagra en una formulación concentrada y categórica los grandes valores sobre los que se asienta una comunidad determinada, además de la forma con que esta ordena sus poderes, procede en América de dos fuentes concretas, la de Locke, con su pacto social básico para asegurar la libertad, yla idea de un higher Law, un Derecho más alto, con claras raices en el Derecho Natural, capaz de prevalecer sobre las leyes ordinarias e, incluso, de erigirse en canon de validez de las mismas. Este concepto de Constitución no se recibirá en Europa, con una excepción parcial en la Constitución austríaca de 1920, hasta esta segunda postguerra mundial, concretamente con las Constituciones italiana y alemana de 1948 y 1949. De aquí pasará, parcialmente, a la Constitución de la V República Francesa de 1958, la portuguesa de 1976 y la española de 1978, con una generalización ulterior a virtualmente todo el constitucionalismo actual. En esta recepción europea de la concepción americana de la Constitución como norma suprema efectiva, invocable ante los Tribunales, canon de validez de las leyes y criterio primero para la interpretación y aplicación de estas, pesó, indudablemente, la experiencia de los totalitarismos europeos, en todos los cuales los dictadores dispusieron a su arbitrio del poder legislativo, haciendo aparecer a la Ley como destructora, y no como protectora, de la libertad". ${ }^{3}$

Este enfoque de las anomalías de la ley, no representa una crítica a la ley tributaria, por el contrario, solo puntualizo que junto a su descollante y formidable posición central de privilegio dentro de la constelación de fuentes del Derecho tributario, como toda elaboración humana, está expuesta a falencias, debilidades y anomalías. 


\section{ANOMALÍAS DE LA LEY}

Identifico como anomalías a una serie de factores distorsionantes de la ley como instrumento general y abstracto en cuya naturaleza intrínseca se encuentra la voluntad popular fundida en un mandato jurídico plasmado en la herramienta legal.

Aún cuando no tenga entidad suficiente para conmover la relevancia de la ley como fuente estos factores afectan al único instrumento con aptitud suficiente para enlazar al Estado y al contribuyente en una obligación tributaria. Se advierte que en la actualidad asistimos a cierta desfiguración de la esencia de la ley, de las motivaciones que la originan. La natural aspiración de la ley desempeñándose como instrumento organizador de la sociedad exhibe alguna debilidad por múltiples factores que, nos parece, se proyectan sobre el Derecho Tributario.

Las anomalías son debilidades, particularismos de la ley que desorientan al operador jurídico. Estos múltiples factores se pueden agrupar en la presiones de los grandes intereses políticos, la autonomía funcional creciente de los organismos públicos, la paulatina pérdida de posición central originaria de los individuos, la evaporación de las notas liberales de la ley, la pulverización de la abstracción y generalidad típicas de la norma jurídica, la heterogeneidad de los contenidos, la ocasionalidad que hace que la ley se sanciones por circunstancias coyunturales y no por el proceso lógico de la necesidad de responder con elaboraciones finamente decantadas, la evaporación de la estatalidad del Derecho, la desaparición del concepto de ordenamiento y la inflación legislativa que desmerece a la ley como instrumento eficaz de la regulación de conductas. Trato de abordar, en lo que sigue, someramente todos esos factores de debilidad.

\section{LA LEY SE DEBILITA ANTE LOS GRANDES INTERESES PÚBLICOS DEL ESTADO Y PIERDE SU FUNCIÓN GARANTIZADORA}

Los intereses superiores del Estado, las razones concretas impostergables que llevan muchas veces a una ardua negociación y armonización de intereses de la más diversa naturaleza: empresariales, sindicales, de fuerzas sociales de hecho, entre varias, desvirtúan a la ley. El Congreso de la Nación, al sancionar una ley tributaria, ¿se ocupa de tutelar el Derecho Tributario o se privilegian otros intereses, también importantes, pero que pueden colisionar con el fin último que es servir al bien común? En ocasiones, la creciente complejidad del Derecho Tributario y el aumento del número de contribuyentes conspiran contra el trabajo de la Administración Tributaria, la cual tropieza con mayores dificultades de control; por eso hay un interés creciente de aquellas por simplificar los procedimientos de recaudación.

Ello trae aparejado el acortamiento de los plazos de los descargos frente a una pretensión fiscal, la imposibilidad de la producción de la prueba, la encrucijada en la que se coloca al contribuyente que debe decidir entre cumplir una pretensión fiscal susceptible de ser cuestionada pero con algún beneficio por el hecho de dar por finalizada la cuestión o embarcarse en una discusión judicial de alcances impredecibles. Entonces, ¿es correcto el ofrecimiento de esos caminos de elección del contribuyente que es tentado a no discutir por el beneficio de alguna disminución en el costo final?, ¿es admisible la simplificación en la investigación de los datos aportados por el contribuyente para resolver rápidamente las contiendas o debemos privilegiar la legalidad estricta?. El jurista no puede pronunciarse de otra manera de defender la legalidad estricta, que es una traducción adecuada de tutelar el Derecho.

La misión del Estado no es solo recaudar sino que en esa tarea, además, debe tutelarse el Derecho Fiscal. Señala más específicamente Zagrebelsky que,

"(...) la crisis de la vinculación de la Administración a la ley previa deriva de la superación, por parte del aparato del Estado, de su función prevalentemente "garantizadora" -es decir, de su función de garantía concreta de reglas juridicas generales y abstractas mediante actos aplicativos individuales y concretos (prohibi- 
ciones, autorizaciones, habilitaciones, decisiones, etc.)-y de la asunción de tareas de gestión directa de grandes intereses públicos. La realización de estas tareas de gestión requiere la existencia de grandes aparatos organizativos que actúan necesariamente según su propia lógica, determinada por reglas empresariales de eficiencia, exigencias objetivas de funcionamiento, intereses sindicales de los empleados (por no hablar de las reglas informales, pero no por ello inexistentes, impuestas por el patronazgo de los partidos políticos)".4

\section{CRECIENTE AUTONOMÍA FUNCIONAL DE LA ADMINISTRACIÓN}

La Administración Tributaria necesita de sus potestades cada vez más amplias, de textura abierta y contornos imprecisos para la realización de sus objetivos en un contexto de permanente cambio y ciudadanos no permeables, necesariamente, al cumplimiento de la ley. Es por ello que la ley se encarga de dotar a la Administración Tributaria de poderes cada vez más amplios, extensos y hasta imprecisos para desarticular el relajamiento evidente en cumplir estas prestaciones voluntariamente. Esto es lo que favorece al hecho de que la Administración Fiscal no se encuentre en una posición de simetría respecto de los particulares administrados pues se incrementan sus prerrogativas o potestades públicas a través de la ley. Se dice que estas prerrogativas, estas potestades desnivelantes, reconocen el límite en la ley. ¿Pero si es la propia ley la que acuerda estas potestades?

"En presencia de objetivos sustanciales de amplio alcance, indicados necesariamente mediante formulaciones genéricas y cuya realización supone una cantidad y variedad de valoraciones operativas que no pueden ser previstas, la ley se limita a identificar a la autoridad pública y a facultarla para actuar en pro de un fin de interés público. Para todo lo demás, la Administración actúa haciendo uso de una especifica autonomía instrumental, cuyos límites, en relación con el respeto a las posiciones subjetivas de terceros, resultan fundamentalmente impreciso. Por tanto, corresponderá también a la Administración establecer la línea de separación entre su autoridad y la libertad de los sujetos. Esto es particularmente evidente (y necesario) en los ya numerosisimos casos en que se confieren a las administraciones funciones a mitad de camino entre la acción y la regulación: las funciones de planificación. Dichas funciones inciden normalmente en el ámbito de la actividad económica: precisamente un ámbito "privilegiado" de la tutela legislativa de los particulares, según la concepción de la legalidad característica del siglo XIX".

Como ejemplos cabe relacionar esta creciente autonomía funcional de la Administración en laš amplias atribuciones otorgadas por las denominadas "leyes antievasión", figuras novedosas para el ordenamiento local como las del "agente encubierto" las facultades para el secuestro e interdicción de mercaderías y una creciente aparición de normas que implican sanciones encubiertas. Estas son las consecuencias desfavorables de la violación de un precepto, no calificadas ni reguladas por el legislador como sanciones pero que su efecto es el de una sanción; son institutos que de un modo u otro, más o menos indirectamente, los utiliza el legislador como instrumentos de reacción hacia un comportamiento no adecuado al precepto.

\section{PÉRDIDA DE LA POSICIÓN ORIGINARIA DE LOS PARTICULARES FRENTE A DETER- MINADOS SECTORES DEL DERECHO}

La inflexibilidad de la norma tributaria hace que el contribuyente, muchas veces, sea tratado como un súbdito y no como un ciudadano. Un enorme caudal de obligaciones formales recaen sobre este, usualmente con costos que son trasladados al contribuyente directamente

4 ZAGREBELSKY, Gustavo, El derecho dúctil, Tercera Edición, Trotta, Madrid, 1999, p. 34.

5 Íbidem, p. 35. 
(los costos derivados de reunir información para el Fisco) revela un cierto carácter tutorial de la Administración para con el contribuyente, alejada de una relación jurídico tributaria igualitaria; todo lo cual se traduce en una posición relativa y débil del contribuyente frente a la Administración.

Zagrebelsky indica que "(..) en determinados sectores particularmente relevantes por la connotación "social" del Estado contemporáneo, se niega el principio de la libertad general salvo disposición legislativa en contrario. En su lugar se establecen prohibiciones generales como presupuesto de normas o medidas particulares que eventualmente las remuevan en situaciones especificas y a menudo tras el pago de sumas en concepto de títulos diversos. Piénsese en las actividades relacionadas con la utilización de bienes escasos de interés colectivo, y por ello particularmente "preciosos" (el suelo, los bienes ambientales en general). La tendencia es a considerarlas prohibidas en general, salvo autorización cuando sean compatibles con el interés público, situación que deberá ser valorada por la Administración en cada caso, y mediante pago por el particular de sumas equivalentes a la incidencia sobre la colectividad de la utilización privada del bien (...). De este modo, frente a los peligros de una libertad sin responsabilidad, resurge la llamada a un "paternalismo" del Estado del que quizás no pueda prescindirse en asuntos como estos".

Por ejemplo, el Código Fiscal de la provincia de Buenos Aires contiene la figura del decomiso de bienes. Esta se aplica a aquellos objetos que se transporten sin documentación respaldatoria. Si se produce esta infracción tributaria, el contribuyente es privado de la mercadería. Puede discutir la procedencia de esa sanción, pero en plazos perentorios y sumamente breves y en el marco de un proceso que se extenderá en el tiempo. Paralelamente puede rescatar los bienes mediante el pago de una multa. El dilema, en- tonces, es contrastar la juridicidad de la cuestión en un proceso largo o pagar una suma de dinero y recuperar los bienes. ¿Esta ley tutela adecuadamente el Derecho Tributario? Parece que no es una adecuada tutela colocar al contribuyente en la disyuntiva de optar por pagar o someterse al tedioso y extenso procedimiento.

\section{PÉRDIDA DE LOS CARACTERES LIBERALES DE LA LEY}

La permanente presencia de conceptos juridicos indeterminados dejan el campo libre para la decisión de la Administración pudiendo dar lugar a posibles invasiones por motivos metajurídicos, en las que el principio de legalidad corre peligro. Por esta razón, se están disipando los caracteres liberales de la ley, concebida como límite a la situación de libertad "natural" presupuesta en favor de los particulares.

La ley pierde el sentido de la orientación. Schick brinda ejemplos relativos a prórrogas y exenciones de impuestos en los que, algunas veces, existen motivos extra-jurídicos para su otorgamiento (por ejemplo, cuando empresas en dificultades financieras anteriormente fueron donantes de fondos para los partidos políticos en ese momento en la gestión del gobierno); por tales razones, exenciones y moratorias en manos del Estado, deben ser interpretadas restrictivamente, dado que, en el Derecho Tributario, no hay lugar para licencias ni regalos, pues estos serían pagados a costa de los demás contribuyentes, lo que no es justo. Bien aclara Schick que "queda, naturalmente, el control politico y la esperanza en una administración que fundamentalmente esté dispuesta a someterse al derecho y a la ley".?

Por ejemplo, la discrecionalidad en el procedimiento tributario es evidente en materia de determinación de oficio pues la Ley de Procedimientos Tributarios faculta a la Administración

6 íbidem, p. 36.

7 SCHICK, Walter, La obligación de las autoridades fiscales de recaudar impuestos. En: Obra colectiva de AMATUCCI, A., GON ZALEZ GARCÍA, E., LEJEUNE VALCARCEL, E., SCHICK, W., UCKMAR, V. y WERLASKI, M., Seis estudios sobre Derecho constitucionale internacional tributario, EDERSA, Madrid, 1980, p. 188. 
a recurrir a hechos y circunstancias conocidos que, por su vinculación o conexión normal con los que las leyes respectivas prevén como hecho imponible, permitan inducir en el caso particular la existencia y medida del mismo. En materia sancionatoria, el juez administrativo está facultado para reducir a su mínimo legal o eximir de sanción, cuando a su juicio la infracción no revistiere gravedad. Existen exenciones tributarias contenidas en una norma determinada, pero dicha norma establece que el contribuyente no goza de ella hasta que la Autoridad de Aplicación la reconozca.

\section{PULVERIZACIÓN DEL DERECHO LEGISLA- TIVO: DETERIORO DE LA GENERALIDAD Y ABSTRACCIÓN DE LAS LEYES}

A la colisión entre autoridad pública y libertad privada se suma un nuevo factor: el creciente deterioro de las características de generalidad y abstracción que debe tener toda ley. Los tiempos actuales están dominados por la pulverización del Derecho legislativo debido a la alta presencia de leyes de carácter sectorial y con marcado anclaje temporal. Se legisla para la cosa concreta en un determinado momento y solicitada por un determinado sector, perdiendo abstracción, generalidad y permanencia. Este es un simple dato del deterioro del concepto clásico de ley.

Las razones de estas características en la norma obedecen al condicionamiento que sufre la sociedad de grupos y estratos sociales que, como señala Zagrebelsky, participan activamente en el "mercado de las leyes", circunstancia que hace aparecer la creciente formación de leyes sectoriales. En suma, se percibe una constante de normativizaciones jurídicas ad hoc, con pérdida para el principio de generalidad.

Señala Zagrebelsky que,

"(...) debe añadirse aún la cada vez más marcada "contractualización" de los contenidos de la ley. El acto de creación de derecho legislativo es la conclusión de un proceso político en el que participan numerosos sujetos sociales particulares (grupos de presión, sindicatos, partidos). El resultado de este proceso plural está, por su naturaleza, marcado por el rasgo de la ocasionalidad. Cada uno de los actores sociales, cuando cree haber alcanzado fuerza suficiente para orientar en su propio favor los términos del acuerdo, busca la aprobación de nuevas leyes que sancionen la nueva relación de fuerzas. Y esta ocasionalidad es la perfecta contradicción de la generalidad y abstracción de las leyes, ligadas a una cierta visión racional del derecho impermeable al puro juego de las relaciones de fuerza".

"El Poder Legislativo, dominado por los partidos y escenario predominante de sus luchas pugnaces, ha dejado de ser el depositario indiscutido y seguro de una voluntad nacional común, y ha sido preciso situar a sulado otra expresión superior del verdadero pacto social básico, receptory regulador de los verdaderos valores superiores en que una comunidad se funda y sobre los cuales, frente a cualquier otra instancia, ha de funcionar. La Ley ha visto asírebajada su antigua preeminencia y ha pasado a ser ella misma un acto jurídico ordenado y no solo ordenador, y como tal sometido a la posibilidad de ser -cosa impensada para la doctrina clásica-enjuiciaday anulada por un Tribunal. Esta es la respuesta, un tanto paradójica, al aserto rousseauniano que vimos más atrás y según el cual "la Ley no puede ser injusta".

Un ejemplo de "contractualización" y "ocasionalidad" los encontramos en la Ley 24.441 , de regulación jurídica del contrato de fideicomiso. El propósito previsto en la Ley -noble y justoes el de la necesidad de crear condiciones más favorables para el acceso a una vivienda digna, tal como expresa el Poder Ejecutivo Nacional en los considerandos del Decreto 780/95 al expresar que:

8 ZAGREBELSKY, Gustavo, Op. Cit., p. 37.

9 GARCIA DE ENTERRÍA, Eduardo, Op. Cit., p. 42. 
"(...) a tal fin se establecieron los instrumentos adecuados para ampliar las posibilidades de financiación a largo plazo para la adquisición de viviendas, simplificando procedimientos, jerarquizando las garantías y creando los institutos legales aptos para desarrollar el mercado secundario de hipotecas, que permitirá la captación de ahorro privado e institucional para proveer recursos a esa financiación".

La norma respondió a una necesidad concreta, a un sector determinado, el inmobiliario, y se sancionó sin el debido autoabastecimiento de su regulación tributaria, a punto tal que la responsabilidad solidaria del fiduciario, por ejemplo, fue establecida por decreto. En efecto, el Decreto 780/95 elevó al fiduciario a la categoría de responsable solidario por vía de deecreto en abierta contradicción con el principio de legalidad fruto de la necesidad de otorgar un ropaje jurídico tributario para este contrato, por entonces, novedoso (subsanado unos años después). Existen en la ley de fideicomiso algunas fórmulas inclusive contradictorias en la actualidad, como la inexistencia del límite mínimo no imponible en el impuesto sobre los bienes personales cuando la ley del impuesto sí lo contiene (la de fideicomiso no). Todo ello demuestra el oportunismo y la falta de reflexión -al momento de sancionarla- de la ley como integrante de un ordenamiento.

\section{VIII.OCASIONALIDAD DE LA LEY: LA LEY COMO RESULTADO DE COLISIONES DE FUERZAS Y SU CONTRACTUALIZACIÓN}

Históricamente se consideraba que la ley tenía la función de definir un orden abstracto de justicia, con aspiración de estabilidad y permanencia, de manera que los individuos podían planificar sus intereses con fundamento en la seguridad jurídica que la norma otorgaba pues ella neutralizaba el sometimiento a la arbitrariedad del Estado. Pero hay nuevas tendencias que interpretan a la ley no como un mandato abstracto y con permanencia en el tiempo sino que, por el contrario, existen normas que resuelven proble- mas concretos, singulares, tangibles. Estas son "leyes-medidas", específicamente destinadas a la solución de una cuestión concreta.

Dice García de Enterría que,

"(...) hoy son caracteristicas las leyes y reglamentos que pretenden articular y organizar "políticas públicas" (fomento del empleo, crecimiento económico, educación, salud, protección del medio ambiente, promoción de viviendas, lucha contra la inflación, contra la sequía, contra otras catástrofes, etc.). Es notoria la diferencia de estas normas de nuevo cuño con las que habia imaginado el pensamiento clásico, la diferencia entre una Ley anual de Presupuestos y sus cada vez más nutridas Leyes "de Acompañamiento" o "de Medidas" con lo que puede significar la Ley que estableció el Código Civil. La Ley-medida no pretende definir un orden abstracto de justicia y tendencialmente permanente; renuncia deliberadamente a las dos cosas y se presenta abiertamente como una norma ocasional, contingente, explicable solo en función de una situación o problema determinados que se pretende enderezar o superar, en todo caso conformar, mediante una determinada política en consideración a un cierto objetivo que se intenta alcanzar en el tiempo, más que en función de una justicia abstracta. Renuncia para ello frecuentemente a la generalidad, que suele ser un correlato de la abstracción, y en la que Rousseau situaba la marca propia yesencial de la Ley, para concretarse a supuestos singulares y especificos."10

Esta ocasionalidad, provisionalidad, contingencia, es perceptible en el Derecho Tributario y en el Derecho Administrativo donde el ordenamiento es mucho más volátil que en cualquier otro sector del Derecho. Se legisla "en tiempo real" y esto conspira con la existencia de Códigos (como la ausencia notable que se registra en nuestro país). Ahora bien, esta es una realidad insuperable, se debe legislar prácticamente "en directo" lo que produce un material normativo imposible de tamizar racionalmente. Esto

10 Íbidem, p. 51. 
conspira con los ansiados valores de certeza, seguridad jurídica, predictibilidad inhibiendo a la contingencia, asistematicidad y oscuridad de las normas, las que a veces no sabemos si están o no vigentes. Todo ello, a su vez, favorece a la excesiva libertad de la Administración y de los jueces también.

La ley, en suma, ya no es garantía absoluta y última de estabilidad, sino que ella misma se convierte en instrumento y causa de inestabilidad. Las consecuencias de la ocasionalidad de las coaliciones de intereses que ella expresa se multiplican, a su vez, en razón del número progresivamente creciente de intervenciones legislativas requeridas por las nuevas situaciones constitucionales materiales. El acceso al Estado de numerosas y heterogéneas fuerzas que reclaman protección mediante el derecho exige continuamente nuevas reglas e intervenciones juridicas que cada vez extienden más la presencia de la ley a sectores anteriormente abandonados a la regulación autónoma de los mecanismos sociales espontáneos, como el orden económico, o dejados a la libre iniciativa indivịdual, como era la beneficencia, hoy respaldada o sustituida por la intervención pública en la asistencia y en la seguridad social. En estos campos, en los que las leyes actúan sobre todo como medidas de apoyo a este o aquel sujeto social y vienen determinadas más por cambiantes relaciones de fuerza que por diseños generales y coherentes, la inestabilidad es máxima y se hace acuciante la exigencia de protección frente a la ocasionalidad de los acuerdos particulares que impulsan la legislación.

La amplia "contractualización" de la ley, de la que ya se ha hablado, da lugar a una situación en la que la mayoría legislativa política es sustituida, cada vez con más frecuencia, por cambiantes coaliciones legislativas de intereses que operan mediante sistemas de do ut des. Las leyes pactadas, para poder conseguir el acuerdo político y social al que aspiran, son contradictorias, caóticas, oscuras y, sobre todo, expresan la idea de que -para conseguir el acuerdo- todo es susceptible de transacción entre las partes, incluso los más altos valores, los derechos más intangibles. "La ley hoy ya no es la expresión "pacíica" de una sociedad política internamente coherente, sino que es manifestación e instrumento de competición y enfrentamiento social: no es el final, sino la continuación de un conflicto; no es un acto impersonal, generaly abstracto, expresión de intereses objetivos, coherentes, racionalmente justificables y generalizadas, es decir, si se quiere, "constitucionales", del ordenamiento. Es, por el contrario, un acto personalizado (en el sentido de que proviene de grupos identificables de personas y está dirigido a otros grupos igualmente identificables) que persigue intereses particulares"."

\section{PÉRDIDA DE LA ESTATALIDAD DEL DERECHO}

La cotidianeidad y las necesidades políticas muchas veces llevan a los Estados a recurrir a las leyes de presupuestos en las cuales incorporan cuestiones tributarias que merecerían una ley ad hoc. Esta técnica legislativa alternativa avanza.

"Resulta completamente insoportable esta técnica de legislar en bloque, asistemáticamente, sin motivación alguna visible simple fruto aparente del arbitrio y no de la razón legislativa, que parece que es la que debiera manifestarse en el debate de las Cámaras (Poder legislativo) según la teoría democrática, de hecho fruto de iniciativas ocasionales y arbitristas de los distintos servicios administrativos, y cuyo texto final resulta normalmente inextricable para el lector incluso más despierto, que necesitará un esfuerzo excepcional para llegar a hacerse cargo del efecto innovativo global que tan expeditivamente se ha introducido en el ordenamiento (...). Todo este extraño y anómalo proceder del Legislativo no está hecho precisamente para facilitar el conocimiento $-y$, por tanto, la fluida aplicación-de las Leyes y más bien hace de la posibilidad de ese conocimiento casi una hazaña esforzada, que solo algunos expertos -entre los que, por supuesto, no me atrevería a decir que yo mismo

11 ZAGREBELSKY, Gustavo, Op. Cit., p. 38. 
me cuente-son capaces de llevar a término, si alguno (...). ¿Qué queda aqui de la Ley como expresión de la voluntad general, viejo mito que luce aún retóricamente en el Preámbulo de la Constitución? ¿O como expresión de una racionalidad ordenadora buscada deliberativamente por las Cámaras? Nada digamos ya de la encendida mitología rousseauniana sobre la inexorable excelencia de las Leyes.".

También cabe afirmar que"(...) la estatalidad del derecho, que era una premisa esencial del positivismo juridico del siglo pasado, es puesta en tela de juicio y la ley se retrae con frecuencia para dejar sectores enteros a regulaciones de origen diverso, provenientes bien de sujetos públicos locales, en conformidad con la descentralización política y jurídica que marca de forma característica la estructura de los Estados actuales, bien de la autonomía de sujetos sociales colectivos, como los sindicatos de trabajadores, las asociaciones de empresarios y las asociaciones profesionales.". ${ }^{3}$

\section{PUlVERIZACIÓN DEL CONCEPTO DE ORDENAMIENTO}

Por la incoherencia que muestra muchas veces la ley, por las contradicciones evidentes entre varios preceptos normativos entre sí, por la exigencia de la reglamentación de una norma so pretexto de que su operatividad devendrá de la pertinente reglamentación, el ordenamiento -como conjunto sistemático y orgánico-pierde sentido, se pulveriza.

Hoy se descarta casi por completo la idea de que las leyes y las otras fuentes, consideradas en su conjunto, constituyan de por sí un ordenamiento -como podía suceder en el siglo pasado-. La crisis de la idea de código es la manifestación más clara de este cambio. En estas condiciones, la exigencia de una reconducción a unidad debe tener en cuenta la crisis del principio de legalidad, determinada por la acentuada pérdida de sentido, pulverización e incoherencia de la ley $y$ de las otras fuentes del derecho. ${ }^{14}$

"La extraordinaria movilidad de las Leyes, que parte de la creencia de que las leyes son capaces de resolver todos y cada uno de los problemas que presenta sin cesar una cambiante sociedad, ha venido a hacer imposible, paradójicamente, el positivismo como método. La formidable e imparable cosecha diaria de nuevos productos normativos impide, como cuestión de puro hecho, integrar todos ellos en un sistema estructurado y armónico. El intérprete del Derecho carece ya, simplemente, de resuello para ese seguimiento exegético de la producción en masa de nuevas normas. El legalismo exacerbado ha matado definitivamente al positivismo! Consecuencia inesperada del predominio formal absoluto de las Leyes, con el que se pensó llegar a eliminar a todas las demás fuentes del Derecho. Pero como, además, ese tipo de producción masiva de Derecho afecta gravemente al propio basamento del sistema jurídico y a sus dos valores centrales, la justicia y la seguridad juridica, he aqui que la multiplicidad de las normas nos ha forzado, paradójicamente, a volver los ojos a los métodos precodificadores de la jurisprudencia, a los que pusieron en marcha los juristas romanos y que nunca han dejado de estar presentes en la conciencia de los hombres de Derecho, al método que prima a los valores sustanciales del Derecho por encima de la envoltura formal de sus normas, y mucho más cuando éstas son tan ocasionales y fugaces como ya nos consta". ${ }^{15}$

Un claro ejemplo de lo expuesto se exhibe en un aspecto del procedimiento tributario muy evidente. Las determinaciones tributarias se

12 GARCÍA DE ENTERRÍA, Eduardo, Op. Cit., p. 89.

13 ZAGREBELSKY, Gustavo, Op. Cit., p. 39.

14 Íbidem, p. 39.

15 GARCÍA DE ENTERRÍA, Eduardo, Op. Cit., p. 103 
apelan, con carácter suspensivo, por ante el Tribunal Fiscal de la Nación. Mientras se sustancia el trámite por ante este tribunal, el curso de la prescripción de los poderes del Fisco para la determinación de deuda también se suspenden, pero estos renacen con posterioridad a la notificación del fallo del Tribunal Fiscal de la Nación. Cuando el fallo es adverso al contribuyente, el renacimiento del curso de la prescripción obliga al Fisco nacional a ejecutar esa deuda por vía del juicio de apremio. Pero usualmente, el contribuyente perdidoso apela el fallo adverso del Tribunal Fiscal de la Nación por ante la Cámara Nacional de Apelaciones en lo Contencioso Administrativo Federal (en plena instancia judicial). En consecuencia, no habiendo resuelto esta laguna normativa, el Fisco no tiene más remedio que apelar -pues, si está al borde de la prescripción, sus potestades fenecerían- $y$, paralelamente el contribuyente, al apelar, ha mantenido viva la apelación. En suma, paradójicamente el contribuyente está discutiendo judicialmente su presunta deuda (aún no firme en sede judicial) cuando el Fisco le ejecuta la misma en un juicio de apremio.

\section{SUPERABUNDANCIA LEGISLATIVA}

La frondosidad normativa (leyes, resoluciones, decretos) provocan la relativización de los conceptos jurídicos y alientan a la inseguridad jurídica. A veces resulta complejo para el contribuyente acceder a todas las disposiciones en vigor, máxime el principio según el cual el derecho se presume conocido, no pudiendo invocarse el error de derecho.

"La Ley es la producida por la desvalorización que ha seguido a una inflación desmedida de las Leyes como consecuencia de su multiplicación incontenible, que, además, ha sido acompañada de un desarrollo desbocado de normas reglamentarias, que complementano ejecutan las Leyes. La vieja idea de una socie- dad libre moviéndose en el cuadro de unos cuantos Códigos y Leyes, claros, concisos y tendencialmente estables, que dejaban a la libertad ciudadana todo el amplio espacio de la vida social así encuadrada con precisión y rigor, esa idea ha dejado paso a la situación actual en que la sociedad se nos aparece inundada por una marea incontenible de Leyes y de Reglamentos". ${ }^{16}$

Villar Palasí, cita a Lord Wilberforce en su discurso del centenario de la Internacional Law Association en una afirmación magistral: "Toda ley debe contener la regulación del futuro. La ley suele ser un buen cerrojo o una magnifica valla, pero cuando el caballo ya escapó. Hoy tenemos buenas leyes sobre urbanismo cuando la ecología urbana es monstruosa ya, normas sobre ahorro de fuentes energéticas cuando se están agotando las existentes, únicas reguladas, cupos para la pesca de la ballena cuando la especie casi se ha extinguido, leyes sobre contaminación cuando no se puede respirar aire puro en casi ninguna ciudad. Tenemos ya casi perfecta legislación sobre la piratería aérea cuando está desapareciendo". Y concluye: "Ourjob is to see things coming -even if they call us unpractical-and to startinformed thinking"(Draft Report for New Delhi Conference, 1975). ${ }^{17}$

\section{CONCLUSION}

Este aporte pretende compulsar una serie de aspectos que rodean a la ley y la jaquean en relación a la confianza y certeza que ella brinda. Merece muchas precisiones, mayores ampliaciones y sustanciales correcciones, pero pretenden enfatizar que la idea que concebimos de la ley como instrumento infalible, puede no ser tan contundente por la simple razón de ser una herramienta creada por el hombre, consecuentemente con las imperfecciones que origina toda elaboración humana. Indudablemente, los principios -que inspiran a la ley-son impermeables a la acción humana y más confiables.

16 Íbidem, p. 47

17 VILLAR PALASÍ, José Luis, La interpretación y los apotegmas jurídico-lógicos, Tecnos, Madrid, 1975, p. 10. 